\title{
A geospatial analysis of market integration: the case of the 2004/5 food crisis in Niger
}

\author{
Michael Shin
}

Received: 20 March 2010 /Accepted: 21 June 2010 / Published online: 16 July 2010

(C) The Author(s) 2010. This article is published with open access at Springerlink.com

\begin{abstract}
Food prices are an important component of the food security equation. Stable prices promote food security, whereas price instability and volatility can contribute to and exacerbate food crises. Understanding market integration, or the co-movement of prices between different markets, can therefore provide important insights into food security and threats to it. The value of a geographic perspective is illustrated through an examination of market integration with spatial analysis. Results from an analysis of the 2004/5 food crisis in Niger indicate that market integration in Niger tends to be local and deteriorates rapidly during shocks or periods of crisis.
\end{abstract}

Keywords Market integration $\cdot$ Prices $\cdot$ Famine $\cdot$ Spatial analysis $\cdot$ Niger

\section{Introduction}

Availability and access to food are key determinants of food security. Therefore, understanding how markets operate, and in particular, the mechanisms by which prices stabilize and fluctuate can provide important insights into a given population's food security situation. The price of food, however, is rarely stable over time. Moreover, price fluctuations in one market may be related to or reflect price movements in other markets. The extent to which price changes in one market location are consistently related to changes in other market locations is generally referred to as market integration or spatial market integration.

\section{Shin $(\bowtie)$}

University of California, Los Angeles,

Los Angeles, CA, USA

e-mail: shinm@geog.ucla.edu
In theory, when markets are highly integrated, food flows freely from markets where there is a surplus to markets where there is a deficit or from areas of production (e.g., rural, agricultural areas) to areas of consumption (e.g., urban centers). Food prices arguably reflect this process; higher prices can be expected in markets where there is a food deficit, and serve as an incentive to suppliers to transport food from surplus to deficit markets. Subsequently, food prices should decline in deficit markets as more food becomes available (i.e. cheaper), thus increasing levels of food security.

When empirically evaluating and assessing market integration, two important and inter-related considerations need to be addressed. The first concerns the geographical extent or spatial dimensions of market integration. Individual markets, and more specifically, prices within individual markets, may indeed be related to each other, but are such geographical relationships uniform, constant or consistent across a region or country? Is there a particular threshold or distance at which market integration deteriorates? Similarly, the second consideration is concerned with the variability in price setting mechanisms over time. In other words, how stable and robust is market integration from one month, one season or one year to the next? These questions are examined by looking at what happened to market integration during the 2004/5 food crisis in Niger. By exploring and assessing the geographic aspects of market integration during a period of crisis, the utility and potential of spatial analytic techniques to contribute to food security research and policies are also illustrated.

\section{Market integration and the 2004/5 food crisis in Niger}

Market analysis is important to food security assessments for three complementary reasons (Beekhuis and Laouali 
2007). First, as markets are capable of reducing the impact of negative shocks, understanding how markets operate provides important insights into the impact and value of various responses in times of crisis (e.g., food aid versus cash transfers). Second, market analysis is in itself an important aspect of food security monitoring. For instance, the systematic collection of price data from various markets provides a baseline for comparison, early warning and analysis. Third, and related to the first point, market analyses inform the ongoing debate as to whether cash transfers are preferable to food aid. It is argued that when markets are well-integrated cash transfers are appropriate because suppliers and traders will respond favorably to increases in household demand. Yet when and where are markets integrated? And what happens to market integration during periods of crisis?

There is wide-spread agreement that market integration is, in principle, good for food security. Despite this general level of consensus from the food security community, formal definitions of market integration tend to vary considerably. For some, market integration simply refers to market locations that are linked together by trade (e.g., Ravallion 1986). This is in contrast to more restrictive definitions that require one-for-one price changes in different market locations (e.g., Goodwin and Schroeder 1991). Similarly, indicators and tests for market integration range from relatively simple correlations to more complex tests for co-integration. Determining whether markets are integrated, and assessing the level of integration with statistical indicators, often requires setting somewhat arbitrary thresholds (e.g., Harriss 1979). In other words, as noted by McNew (1996), market integration is more frequently premised upon statistical criteria than economic phenomena.

Notwithstanding the differences in definition and measure described above, research from different countries shows that the markets for various goods, ranging from cereals to livestock, are in many cases integrated (Lele 1967; Palaskas and Harriss-White 1993; Fafchamps and Gavian 1996). The degree to which such markets are integrated is in large part contingent upon how specific locations (i.e. markets) are linked or connected together and are able to overcome the friction of distance (i.e. geography). In some contexts, transportation and communications infrastructure arguably supports and promotes high levels of market integration, but in other areas a lack of such infrastructure and information may inhibit market integration. The absence of infrastructure does not necessarily preclude market integration, but it may limit the efficiency, stability (i.e. levels) and geographic extent of such integration. Therefore, in contexts where food security is a concern, evaluating the stability and geographic extent of market integration may provide important insights into when and where surveillance or responses need to be targeted to minimize the impact or perhaps prevent impending food crises.

One country where food security has long been a concern is Niger (Devereux 2009). Situated in the Sahel of West Africa, Niger is a landlocked country that contains a vast expanse of the Sahara desert in the north and subtropical and even tropical climates in the south. With an estimated population of around 13 million people, primarily located in the south of Niger, it is projected that this figure will double by the year 2025 (UNPOP 2007). Niger ranks 174th out of 177 total countries in the 2007/8 UN Human Development Index, in large part due to its low life expectancy (56 years), relatively high levels of child malnutrition and low per capita income. A large proportion of Nigeriens are employed and engaged in rainfed agriculture, with the primary food staples being millet and sorghum. This mix of environmental, demographic and economic factors leaves much of the population of Niger vulnerable to food shortages and crises.

The most recent crisis occurred in 2004/5, and as with most food crises and famines, there were several contributing factors. The beginnings of the crisis were linked to the locust invasion and failed rains of late-2004 that resulted in considerable amounts of damage to grasslands and the loss of millet and sorghum yields across the pastoral and agropastoral zones of Niger (see Fig. 1). Subsequently, early warnings of food insecurity were issued as were requests for food aid (FAO 2005). Markets began to respond to the reduced levels of agricultural production with price increases in January 2005, which left millions of Nigeriens unable to purchase needed amounts of food (Eilerts 2007).

Figure 2 charts the evolution of millet prices in markets across Niger from January 2002 to October 2006 as a series of box-and-whisker plots. The inter-quartile range of monthly price data is portrayed as a vertical box bisected by a line that represents the median value, and the whiskers represent the upper- and lower-extremities of the data. In addition to illustrating the trend in prices, the variability in the range of prices can also be ascertained from such plots. Similarly, Fig. 3 overlays average monthly price profiles for millet, beginning with the harvest period (October-November), from 1997 through 2006. The August 2005 peak of the food crisis as measured by millet prices is clearly evident in both figures.

The response to the crisis by the Government of Niger and the international community was largely directed to the poorest and most vulnerable populations of the pastoral and agro-pastoral zones of the country (Eilerts 2007). However, the areas most visibly affected by the crisis were located in the relatively wealthy parts of Maradi and Zinder, and the agricultural areas along Niger's southern border with Nigeria. Why? Given the proximity and dominance of the 
Fig. 1 Livelihood zones of Niger. Adapted from Famine Early Warning Systems (FEWS) Net

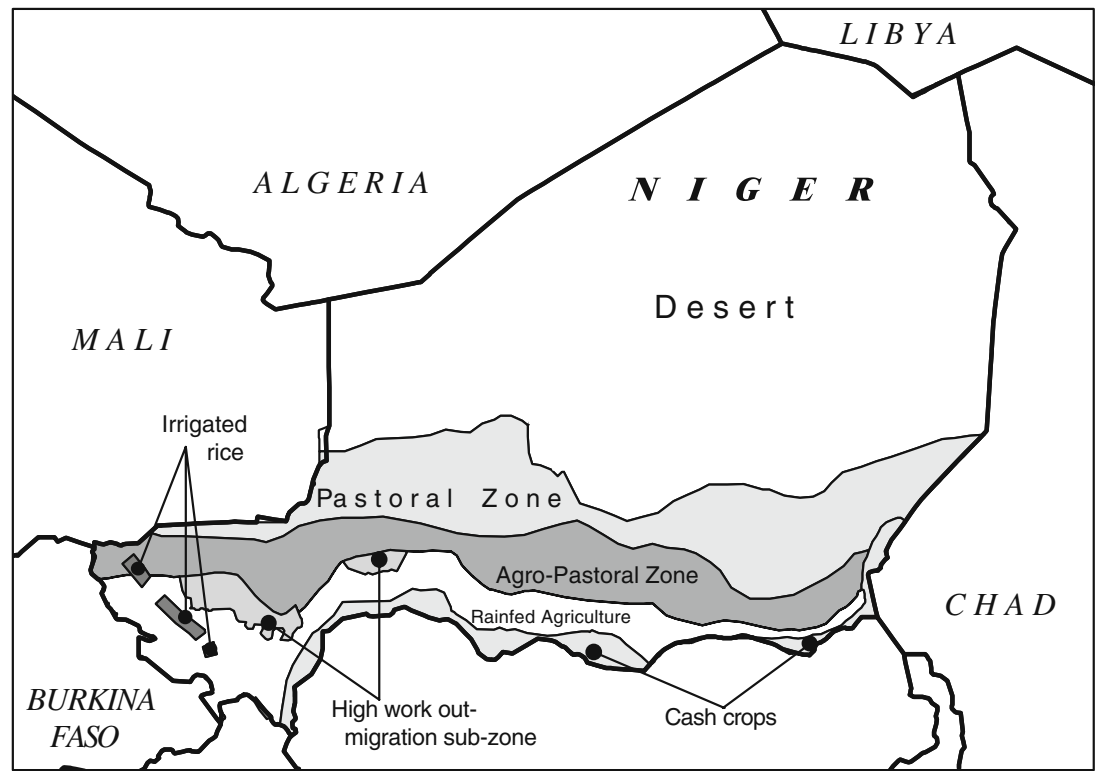

Nigerian market, there is an incentive for farmers to raise cash crops for export. Furthermore, there are wellestablished financing and credit systems available in the area.

In this highly competitive environment, poor farmers and wage laborers are often caught in a vicious cycle of taking out loans under less than favorable terms (i.e. borrowing during lean months when prices are high, making in-kind payments for the value of the original loan during harvest when prices are low). If a harvest is

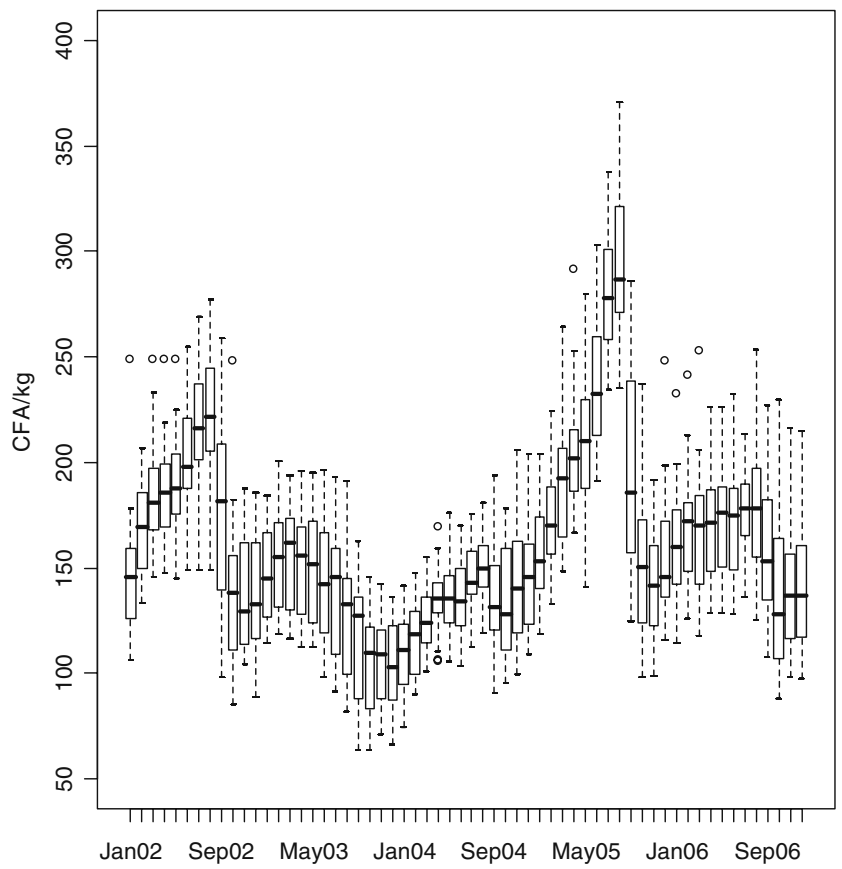

Fig. 2 Box-and-whisker plot of millet prices in markets across Niger, 2002-2006 mediocre, the poorest become even more impoverished due to the timing of higher prices, and subsequently, higher loan repayments, and the downward spiral is often perpetuated. When prices increase significantly, as was the case in early-2005, a large segment of this already vulnerable population becomes food insecure. In this regard, across much of southern Niger, the 2004/5 food crisis was less about locusts and failed rains and more about pre-existing, unfavorable market conditions that in turn facilitated and exacerbated the crisis (Aker 2008; Eilerts 2007; Sanchez-Montero 2007).

What is apparent in hindsight is that the 2004/5 food crisis was in fact two or possibly more related crises (Crombé and Jézéquel 2009; Mousseau 2006; Cornia and

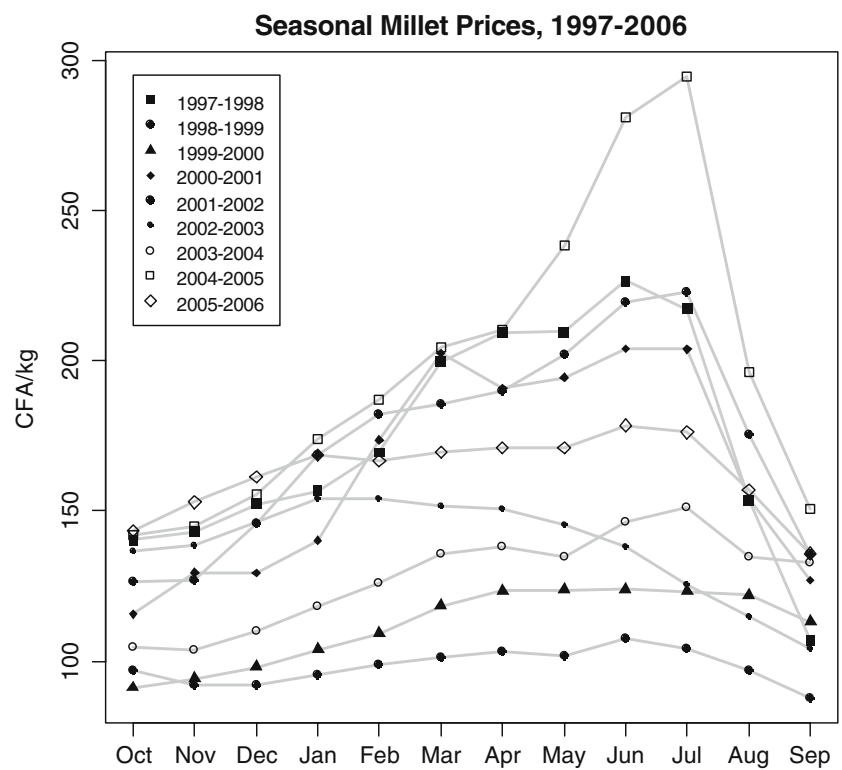

Fig. 3 Seasonal averages of millet prices 
Deotti 2008). The first occurred in the pastoral and agropastoral zones and was more or less anticipated, but the second that struck the southern parts of Niger was not. With regard to the former, the 2004 drought and locust invasion adversely affected the food entitlements of pastoralists and small farmers whose herds and crops were decimated. Warnings were issued and requests for support from donors made in November 2004, but by July 2005 less than ten percent of requested funds had been received (Mousseau 2006). As demand for food increased, and as food security continued to deteriorate during this time, the limited response and intervention only made matters worse. Though there is some debate whether or not initial requests for food aid and financial support were sufficient, the images of malnourished children that appeared in June-July 2005 served to mobilize donors and the international community at large.

Much of the discussion and debate surrounding the causes of the 2004/5 food crisis in Niger is concerned with the roles and types of intervention or lack thereof (Crombé and Jézéquel 2009; Cornia and Deotti 2008). As noted above, both the poor timing and limited scale of the responses by the Nigerien government and the donor community arguably exacerbated the crisis. The lack of intervention by the Nigerien government and the decision to depend upon food imports and the international market proved to be crucial because of the length of time that it took for food to reach those in need. Consequently, by July 2005, the National Food Security Reserve of Niger, which was established to respond to and prevent such food crises, had no more food or money to distribute (Mousseau 2006).

The 2004/5 food crisis also underscores the relatively disadvantaged position of Niger within the regional Sahelian cereal markets, which contributed to the second crisis alluded to above. Though the crisis originated in the pastoral and agro-pastoral zones and initially impacted herders and small farmers, the most pernicious effects and visuals of the crisis came from the south and involved malnourished children. Given its location, length of shared border and ethnic and familial ties, a considerable amount of cross-border trade occurs between the south of Niger and Nigeria (WABI 2006; Mousseau 2006). Such trade often occurs on very uneven and unequal terms given Nigeria's climatic advantages, access to the ocean, and the overall size and strength of the economy, especially when compared to Niger. Add to this speculation, unfavorable exchange rates and terms of trade, price volatility and unregulated markets where the laws of supply and demand take precedence over morals and human need, domestic and regional market failures, such as that which occurred in 2004/5, are the result (Cornia and Deotti 2008).

As population pressure mounts and agricultural plots decrease in size in what is already one of the most densely populated areas of Africa, more people will depend upon cash to make food purchases. Understanding markets, and more specifically the stability and fluctuation of food prices within markets, is therefore central to improving and ensuring the food security situation of those in Niger and across the Sahel (Aker 2008; Dirba and Renk 2007; WABI 2006). The next section describes and illustrates how geospatial data and analysis can be used to examine and understand the geographical and temporal dynamics of market integration as it relates to food security.

\section{Geospatial data, information and analysis: Looking beyond imagery}

There is a wide range of geospatial data available to food security analysts, researchers and decision-makers. Among the most commonly viewed geospatial data products for food security purposes are remotely sensed images. Such images are often used to determine and assess the likelihood of drought, crop yields and rainfall amounts, and support early warnings of food insecurity as was the case in Niger described previously. Such image maps, derived from satellites, represent the surface of the earth as an array of identically-sized cells (called grids or rasters) of particular dimensions (e.g., $1 \mathrm{~km}$-by-1 km). The dimension of a single cell, or its resolution, corresponds to the smallest feature that can be discerned in the image. In addition to the thematic data contained within each cell, such as above or below average levels of vegetative vigor or greenness, the geographic locations of each cell are also known. For instance, the precise latitude and longitude of the cell vertices or centroids are known.

Complementing imagery or raster data are vector data. Unlike the raster data model that represents real-world features as a continuous surface, the vector approach models the world as a collection of points, lines and polygons (see Fig. 4 a $\&$ b). Points are described by geographic coordinates and correspond to precise locations on the surface of the earth; lines comprise an ordered series of points; and, polygons are an ordered series of points with an identical starting and ending point that circumscribe an area. Geographic coordinates, such as latitudes and longitudes, are easily obtained from global positioning systems (GPS) receivers which can then be imported into a geographic information system (GIS) for visualization and analysis. Within the vector approach, for example, cities can be represented as individual points, rivers as lines, and lakes as polygons. Each particular vector feature (i.e. point/ city, line/river, polygon/lake) is also typically associated with a database that contains information about it. For instance, population data can be linked to city locations, stream-flow data can be associated with river segments and 
Fig. 4 a \& b. The Normalized Difference Vegetation Index (NDVI) map (left) for the Horn of Africa is an example of a raster data set and is used to measure vegetative vigor. Greens represent healthy vegetation, reds denote unhealthy and sparse vegetation (e.g., due to possible drought or failed rains), grey is bare land and blue is water. The map on the right is an example of a vector data set, also for the Horn of Africa. Capital cities are drawn as point features, rivers are drawn as linear features and international boundaries are polygon features. Source: Global Information and Early Warning System (FAO-GIEWS) Workstation. Please refer to the online edition for a colour version of this figure
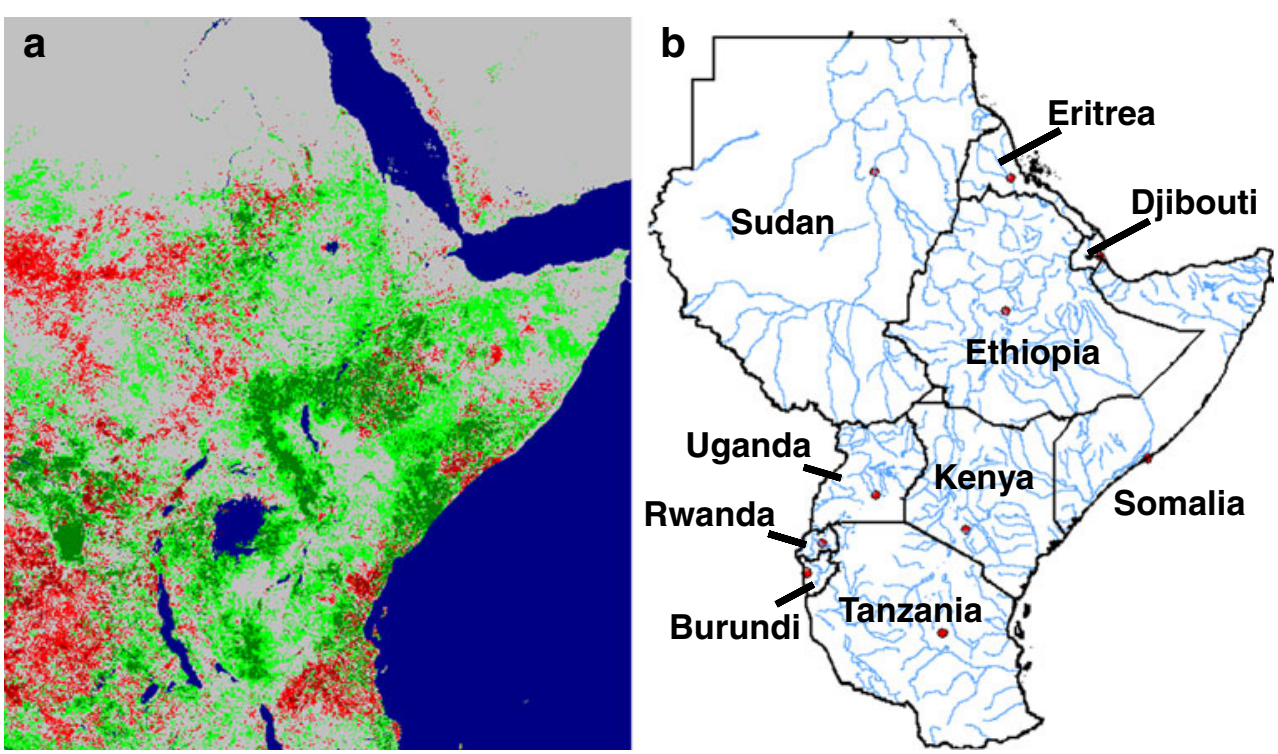

forests can be classified according to species richness. Insights into the geographic aspects and dynamics of various phenomena can thus be gleaned by associating such attribute data with locational information.

Another useful aspect of the vector data model is that it is topological. In other words, the spatial relationships that exist between points, lines and polygons can be extracted and summarized from the vector data model. For instance, internet mapping sites use topological information to calculate optimal driving routes between two different locations. Within the context of GIS, topological information enables automatic error checking, facilitates the calculation of precise distances and areas, and also permits the evaluation of spatial patterns with geo-statistics.

Topological information such as distances between markets, for example, can also be used to assess and evaluate the geography of market integration. Transport costs, which are a function of distance, are recognized to be a key expenditure for suppliers in nearly all sectors of the economy. Generally, the cost of traveling greater distances that is borne by suppliers tends to be passed on as higher prices to consumers. The opposite is also true. Prices tend to be lower near sites of production. Such differentials in distance to markets contribute to the underlying economic geography of regional, national and even global markets. By linking prices to market locations, and comparing prices between proximate and distant markets, the geography of market integration can be assessed.

The Agricultural Market Information System (SIMA) of Niger that was established in the early-1990s provides price information for various foodstuffs from over 40 markets on a regular basis. SIMA also serves as a useful model that can be replicated in other countries and regions concerned with food security. Given the coverage of data from SIMA, a variety of analyses and comparisons can be carried out. For instance, current price trends and events (e.g. shocks and spikes) can be compared to previous years or seasonal averages. Moreover, as prices are collected for numerous markets across Niger, such market data are inherently geographic and can be incorporated into a geographical information system (GIS) to visualize and analyze market integration.

In the absence of information about how markets are related and connected to each other, the distance between markets serves as a reasonable (though highly simplified) proxy for topological relationships. Using GIS to determine Euclidean distances between respective markets, various distance thresholds can be used to assess the geographic extent of phenomena such as market integration. For purposes of illustration, topological information is used to perform a $k$-nearest-neighbor analysis of market integration for markets within Niger. It is understood that agricultural trade across West Africa and the Sahel is indeed crossborder (i.e. international), but for clarity the following worked example is limited to Niger. Supplemental data and information, such as travel time or road-based distances could also be used if available. The movement of prices is assessed and evaluated between the $k$ nearest neighbors, where $k$ is the number of markets that constitute a particular neighborhood. Figure $5 \mathrm{a}-\mathrm{e}$ map the $k$-nearest neighbors for markets in Niger, for all $k$, one through five.

Having established the linkages between markets in Niger, local or neighborhood levels of market integration are measured for each market using the local Moran's I statistic. As a local indicator of spatial association (LISA), the local Moran's statistic calculates the correlation of standardized millet prices between each market and its 
Fig. 5 a-e. Market locations and $k$-nearest neighbors in Niger

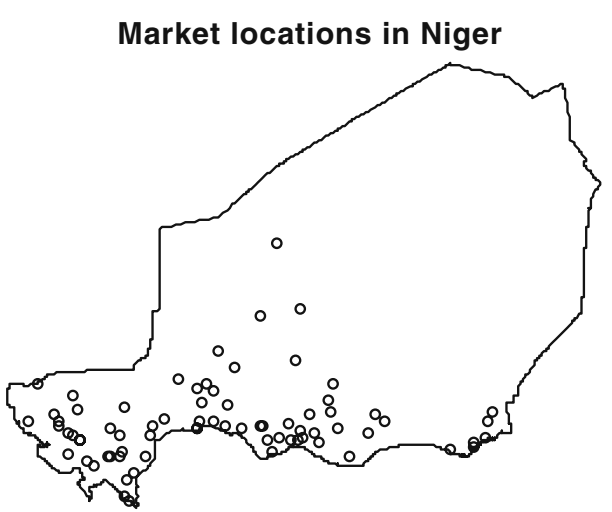

$\mathrm{K}$ nearest neighbors, $\mathrm{k}=\mathbf{2}$

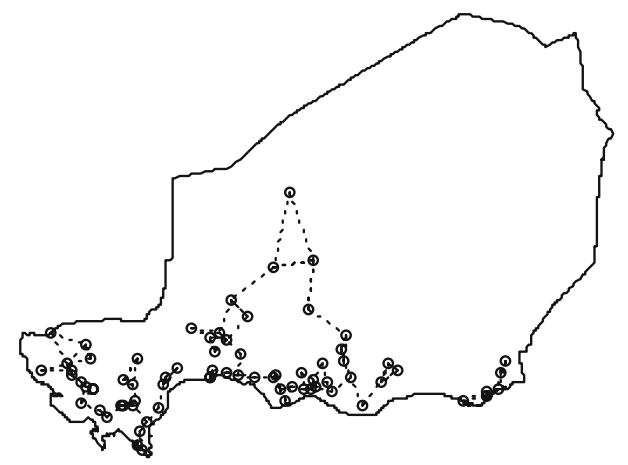

$K$ nearest neighbors, $k=4$

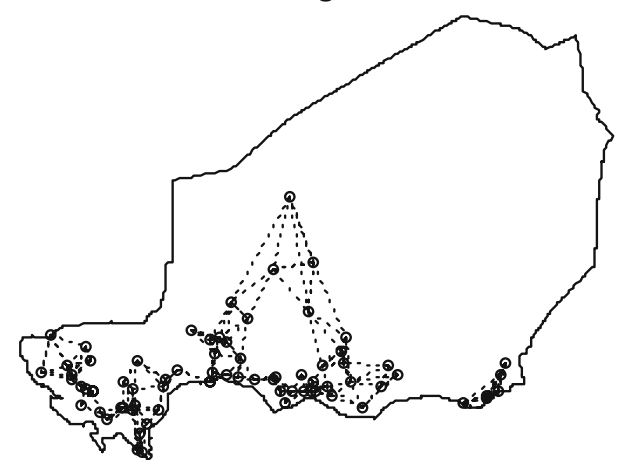

$\mathrm{K}$ nearest neighbors, $\mathrm{k}=1$

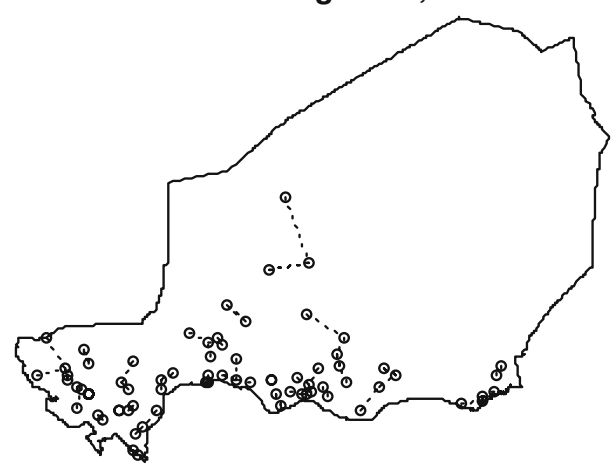

$\mathrm{K}$ nearest neighbors, $\mathrm{k}=\mathbf{3}$

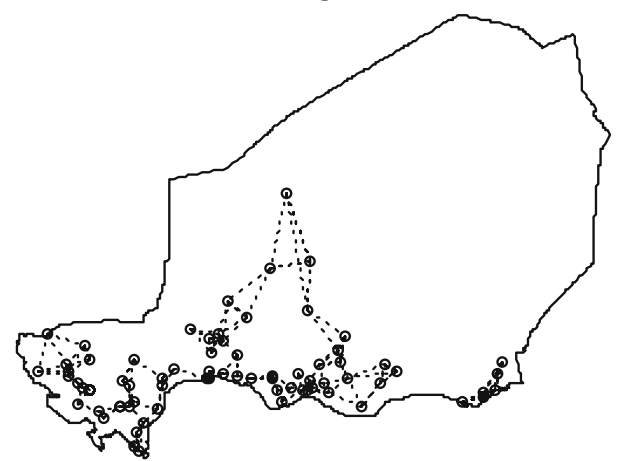

$\mathrm{K}$ nearest neighbors, $\mathrm{k}=\mathbf{5}$

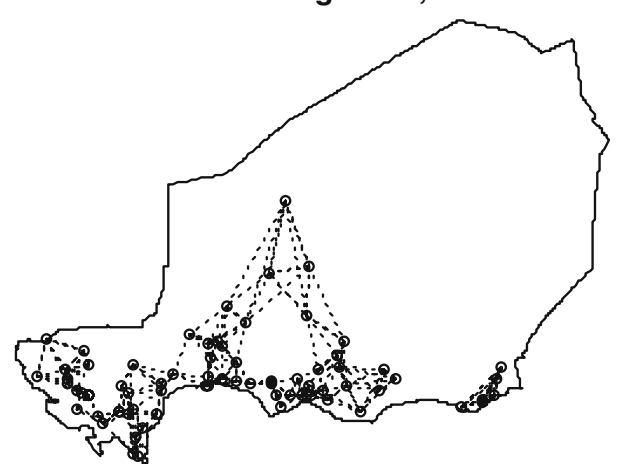

$k$-nearest neighbors (see Anselin 1995). The local Moran's I statistic is formally expressed,

$I_{i}=\frac{z_{i}}{\sum z_{i}^{2}} \sum_{j} w_{i j} z_{j}$

where $z$ is the standardized price of millet, and $w$ is an element of the row-standardized spatial weights matrix, $\mathbf{W}$, that summarizes the geographic linkages between markets (i.e. identifies nearest neighbors). In essence, the local Moran's statistic calculates the relationship between each observation (i.e. market) and the weighted average of neighboring observations.

One of the features of the local Moran's statistic is that values can be plotted and viewed as a scatterplot. With respect to this analysis of market integration, market locations with high millet prices that are surrounded by markets with similarly high prices are situated in the upperright quadrant. Low prices surrounded by low prices are found in the lower-left quadrant. Market prices within these two quadrants are considered to be spatially autocorrelated or spatially dependent. Conversely, the upper-left and lower-right quadrants contain low prices surrounded by high prices and high prices surrounded by low prices, respectively. Markets falling in these two areas are classified as spatial outliers. Figure 6 presents a set of four Moran's scatterplots that exhibit varying degrees of spatial dependence for millet prices in May for $k=2$ and $k=5$ nearest neighbors, as well as for August and September $(k=$ 2) during the crisis year. Of particular interest is the spatiotemporal instability (volatility) of market integration as the crisis progresses. 
Fig. 6 Moran's scatterplots for millet. Market prices are measured in deviations from the mean. Markets where prices are high, and that are linked to other nearby markets with similarly high prices are in the upper-right quadrant. Conversely, markets with low millet prices that are linked to nearby markets with similarly low prices are in the lower-left quadrant. Markets with high prices, but that are linked to markets with low prices are in the lower-right quadrant, and markets with low prices, but linked to nearby markets with higher prices fall in the upper-left quadrant. The slope of the dashed fitted regression line is equal to the global Moran's I statistic
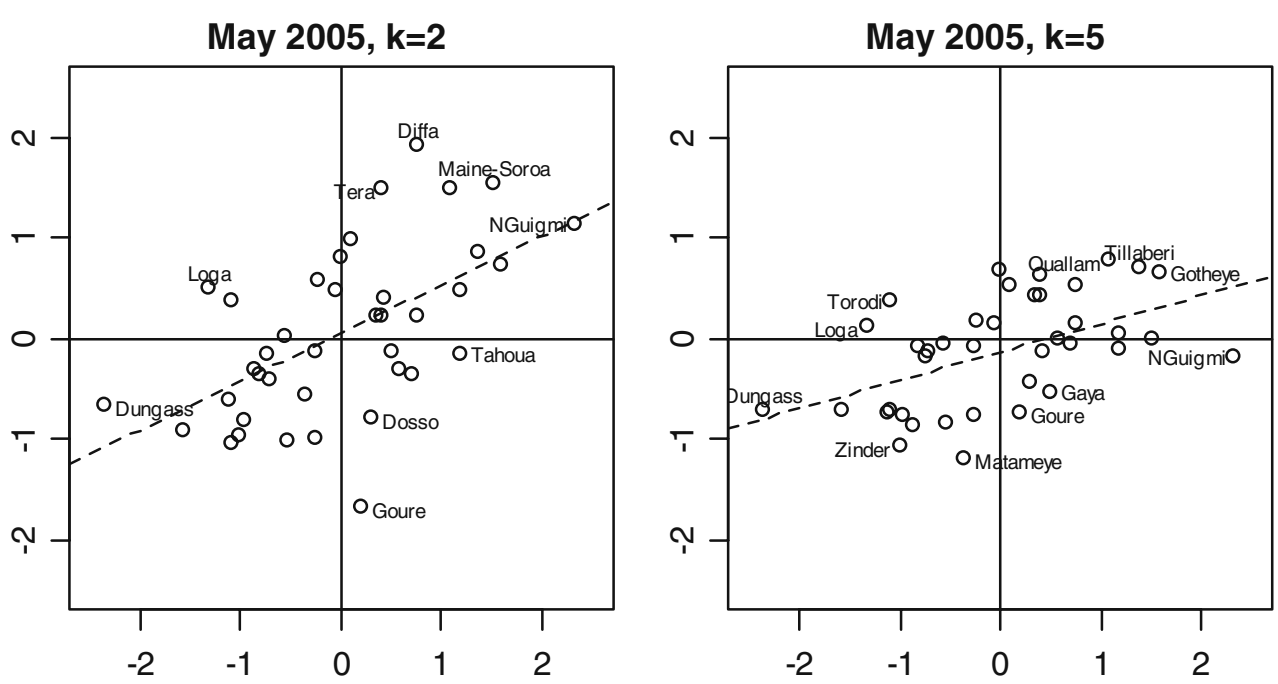

August 2005, k=2

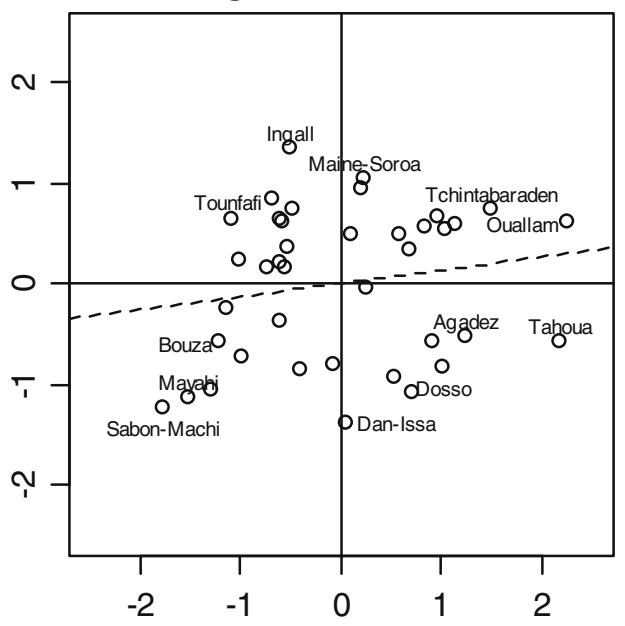

September 2005, k=2

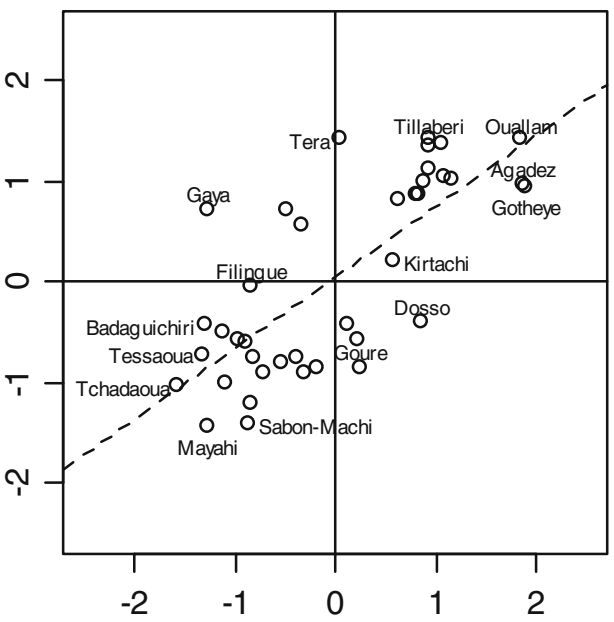

Another useful feature of the local Moran's statistic is that the mean value of all local Moran's values for a given data set is equivalent to the global Moran's I (for details, see Anselin 1995, 1988). The global Moran is frequently used in geographic research to detect and evaluate the presence of spatial autocorrelation or the clustering of similar values within a data set. Values of the global Moran fall between -1 and +1 . A Moran's value of 1 , or perfect spatial autocorrelation, denotes that the value of one observation can effectively be predicted by knowing the values of neighboring observations. Positive values, and hence, positive spatial autocorrelation indicate the geographic clustering of similar values, while negative values denote a chessboard-like pattern of dissimilarity or randomness.

Figure 7 plots global Moran's I values for millet prices for each month during the 2004/5 crisis in Niger and for all $k$, one through five. Three features of particular interest are evident in this graph. First, market integration appears to be quite local in most months, at $k=2$, and then tapers off. In other words, millet prices in most markets tend to be most

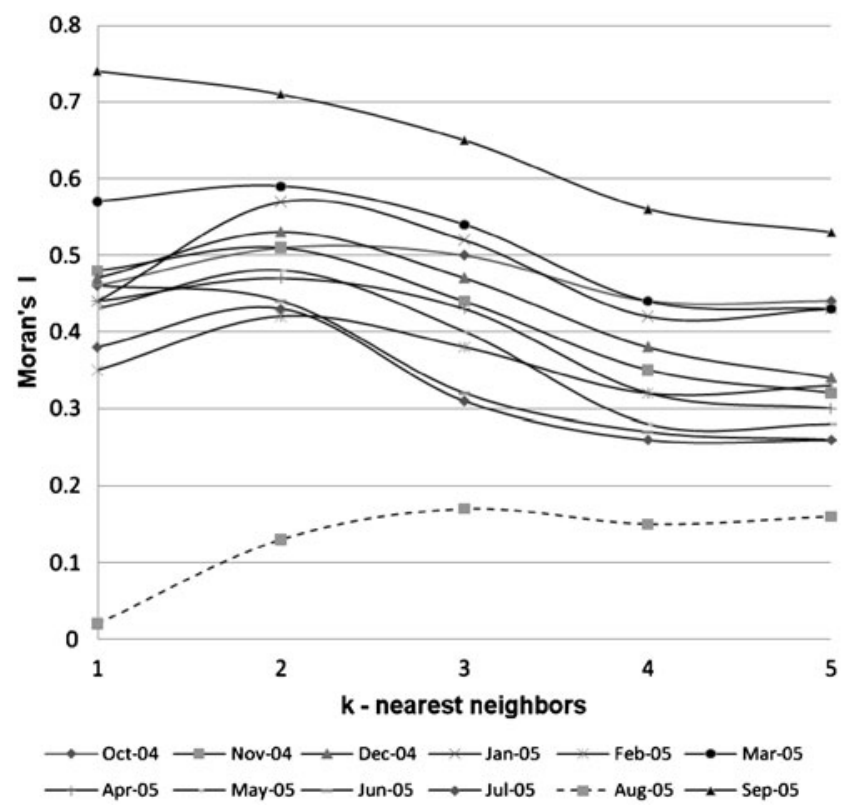

Fig. 7 Global Moran's values for each month and $k$-nearest neighbors 
correlated with the nearest two markets. During the lean season, roughly May through August, levels of integration as measured by Moran's I tend to be lower than other months of the year. Whether or not such patterns are an artifact of the $2004 / 5$ crisis, or reflect seasonal and geographic patterns, is unclear. Furthermore, the role and influence of larger or crossborder markets merit further investigation. Nonetheless, such information about the geographic linkages and extent of markets can inform policies regarding market regulation, the introduction and placement of local safety nets as well as aid distribution.

Second, and in relation to the previous point, local market integration appears to deteriorate as millet prices increase, and more or less collapses at the peak of the crisis in August 2005. This result is quite informative because it is widely understood and accepted that the domestic and regional markets indeed failed in 2004/5 (Cornia and Deotti 2008; Mousseau 2006). This graph illustrates just how quickly the market collapsed in August 2005 and also shows the geographic disintegration of local market linkages (i.e. low Moran's I values). Given the vulnerability and fragility of the Nigerien millet market, efforts to strengthen ties (e.g., through transport or communication networks) between proximate markets may be warranted.

Finally, market integration recovers in dramatic fashion in September 2005, lending support to the argument that markets are able to respond quickly to shocks. This rapid and dramatic recovery of the Nigerien domestic millet market may also be a reflection of the asymmetry of the Sahelian market (i.e. the highly vulnerable, if not dependent, position of Niger relative to Nigeria). Such a recovery arguably reinforces the need to introduce market regulations that minimize price fluctuations and shocks, and also maintain both domestic and cross-border market linkages in times of crisis. Though this analysis did not include markets in Nigeria, the influence and impacts of prices are more than likely reflected in several Nigerien markets.

By linking prices to locations, important insights into the geography of market integration are obtained. Specifically, during the 2004/5 food crisis in Niger, market integration was both geographically and temporally unstable. Future research needs to determine whether or not these geographical and temporal patterns are consistent with other crisis or non-crisis years across the broader Sahelian cereal market, or if such patterns merely reflect the intrinsic nature of market integration in Niger.

\section{Conclusions}

Food crises are the result of continuously evolving and complex sets of environmental, social, economic and political circumstances and events. The 2004/5 food crisis in Niger was no different, and in fact, underscores the need to continue and extend market-based analyses in order to understand and respond to food crises in the future. Through the use of spatial analysis, the geographical and temporal dynamics of market integration are illustrated. With regard to the 2004/5 food crisis in Niger, results indicate that market integration is quite localized and highly fluid, if not volatile, from one month to the next. Though the rapid deterioration of market integration is a cause of concern as a food security crisis evolves, the resilience of markets across Niger and their ability to recover quickly from price volatility, are likely to be key factors to mitigate crises and ensure food security in the future.

As with most analyses, the results presented above lead to more questions than answers. For instance, are levels of market integration similar for other products, such as livestock or cash crops, or for the terms of trade between different goods? Also, how can local and regional market asymmetries, such as those that result from cross-border trade between Niger and Nigeria, and across other areas of the Sahel and Africa, be captured or measured? Though distance-based and nearest neighbor analyses may simplify the complexity of factors underlying market integration, in the absence of data and information about trade networks and linkages, such techniques can provide useful and timely insights about the geographic extent and robustness of market integration and can be applied to other contexts where food security is a concern.

Acknowledgements This paper was prepared during a research visit to the Global Information and Early Warning System (GIEWS) of the Food and Agriculture Organization (FAO), Rome Italy. Special thanks to Henri Josserand, Jean Senahoun, Kisan Gunjal, Gary Tounkara, Marco Boscolo and the anonymous reviewers for their comments, suggestions and insights. All views expressed herein are solely those of the author.

Open Access This article is distributed under the terms of the Creative Commons Attribution Noncommercial License which permits any noncommercial use, distribution, and reproduction in any medium, provided the original author(s) and source are credited.

\section{References}

Aker J (2008) Rainfall shocks, markets, and food crises: evidence from the Sahel-Working Paper 157. Center for Global Development, Washington, DC

Anselin L (1988) Spatial econometrics: methods and models. Kluwer, Dordrecht

Anselin L (1995) Local indicators of spatial association-LISA. Geogr Anal 27:93-115

Beekhuis G, Laouali I (2007) Cross-border trade and food markets in Niger: why market analysis is important for humanitarian action. Humanitarian Exchange Magazine 38:25-27 
Cornia G, Deotti L (2008) Niger's 2005 food crisis: extent, causes and nutritional impact. European Development Research Network working paper $2008 / 15$

Crombé X, Jézéquel J-H (2009) A not-so natural disaster: Niger 2005. Columbia University Press, New York

Devereux S (2009) Why does famine persist in Africa? Food Security $1: 23-35$

Dirba G, Renk S (2007) Market analysis in emergency food security assessments. World Food Program, Rome

Eilerts G (2007) Niger 2005: not a famine, but something much worse. Humanitarian Practice Network. http://www.odihpn.org/ report.asp?id $=2789$

Fafchamps M, Gavian S (1996) Spatial integration of livestock markets in Niger. J Afr Econ 3:366-405

Food and Agriculture Organization (FAO) (2005) Increasingly Serious Food Security Situation in Parts of the Sahel. http://www.fao.org/ giews/english/shortnews/sahel050506.htm

Goodwin B, Schroeder T (1991) Cointegration tests and spatial price linkages in regional cattle markets. Am J Agric Econ 73:452-464

Harriss B (1979) There is a method to my madness: or is it vice versa? Food Res Inst Stud 17:197-218

Lele U (1967) Market integration: a study of sorghum prices in western India. J Farm Econ 49:147-159

McNew K (1996) Spatial market integration: definition, theory and evidence. Agric Resour Econ Rev 22:191-207

Mousseau F (2006) Sahel: a prisoner of starvation? A case study of the 2005 food crisis in Niger. Oakland Institute, Oakland

Palaskas T, Harriss-White B (1993) Testing market integration: new approaches with case material from the West Bengal food economy. J Dev Stud 20:1-57

Ravallion M (1986) Testing market integration. Am J Agric Econ 68:102-109
Sanchez-Montero M (2007) The 2005 Niger food crisis: a strategic approach to tackling human needs. Humanitarian Practice Network. http://www.odihpn.org/report.asp?id=2793

United Nations Population Division (UNPOP) (2007) World Population Prospects: Niger. http://esa/un.org/unpp

West African Borders Initiative (WABI) (2006) Food security and cross-border trade in the Kano-Katsina-Maradi $\left(\mathrm{K}^{2} \mathrm{M}\right)$ Corridor. Sahel and West Africa Club/OECD, Paris

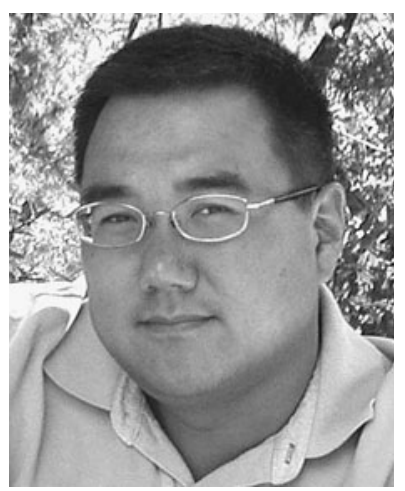

Michael Shin is Associate Professor of Geography at UCLA, Faculty Associate at the UCLA Center for Health Policy Research, and co-chair of the Spatial Demography Group at the California Center for Population Research (CCPR). The aim of Professor Shin's work is to highlight how and why geography matters through the use of geographic information systems (GIS) and related geospatial technology (e.g. GPS, remote sensing), spatial analysis and geo-statistical methods. His publication record includes work on political behavior in the US and Italy, economic globalization, the geography of health, and the influence of geospatial technology on democracy. He has also served as a geospatial technology expert/ consultant on a range of projects related to food security. 